\title{
Plan for recycling water in Billings
}

\author{
Zheng Liu \\ School of North China Electric Power University, Baoding 071003, China \\ hbxt3281510@163.com
}

Keywords: interpolation curve, water consumption, correlation coefficients.

\begin{abstract}
This paper mainly focuses on providing a plan for recycling water in Billings. We divide urban water consumption into living water consumption, industrial water consumption and public water consumption. Using interpolation curve fitting, we separately predict the water consumption in these aspects above. Our forecast result is that 165.67 billion cubic meters water will be consumed in the future 30 years. In addition, we use power function in model 2 to optimize model 1 . Then, the number turns to173.40. In the sensitivity, we analysis several correlation coefficients that mainly influence the results separately.
\end{abstract}

\section{Introduction}

Recycling water is a kind of method appropriately disposing industrial waste water, coming from a closed cyclic water system composed by a factory, a workshop, a water supply system and a drainage system(as shown in Figure 1). In this process, there will be no supplement or a little supplement of fresh water, and no discharge or less discharge of waste water in the meantime ${ }^{[1]}$.

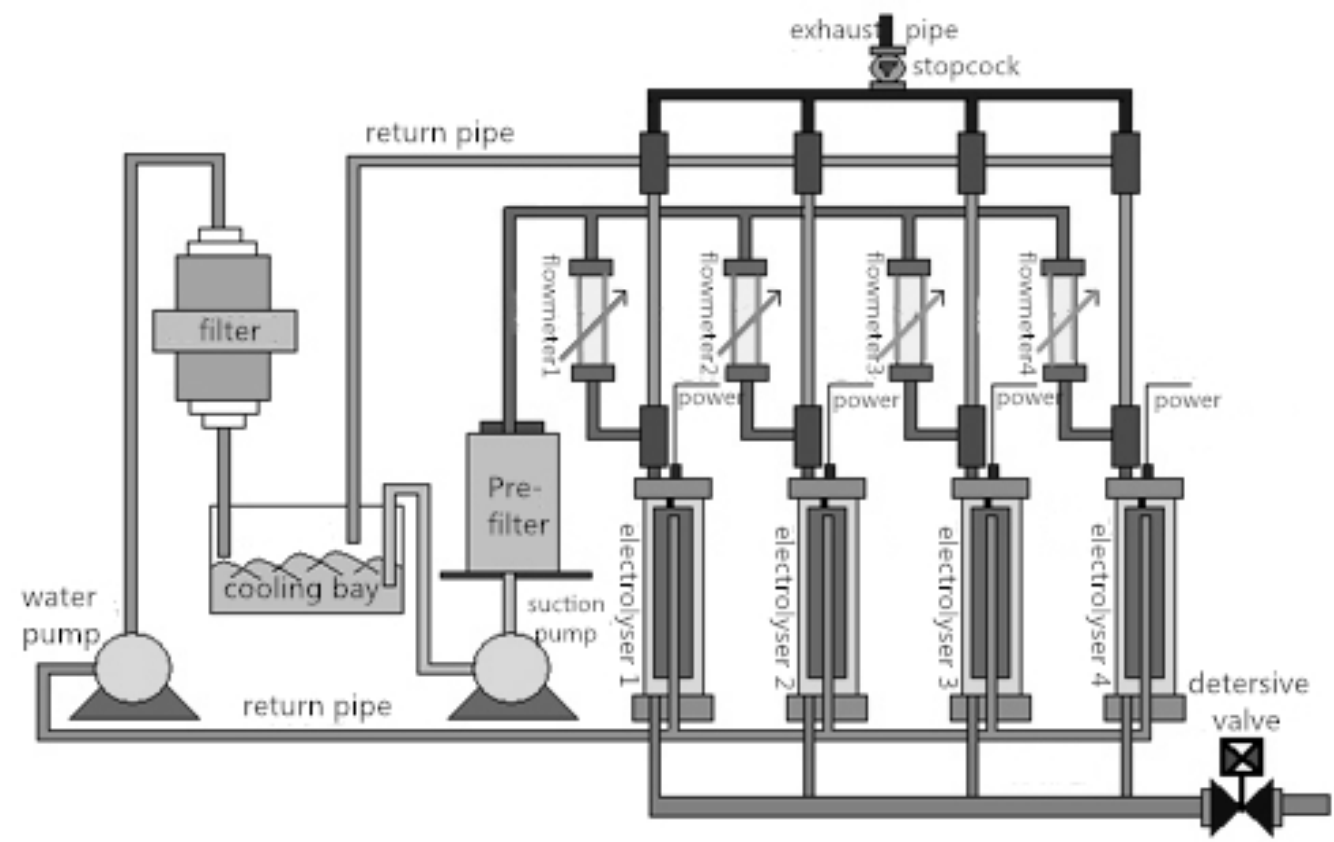

Fig. 1: Industrial waste water treatment system.

We analysis the urban water consumption of Billings consist of living water consumption, industrial water consumption and public water consumption. To face the Shortage of water resources, forecasting and analyzing the total water consumption of Billings in the next 30 years will make sense. 


\section{Model Theory}

\subsection{Model Overview}

The below part of figure 2 shows the flow chart of sewage treatment. In this procedure, sewage treatment process is a pure physical process, there is no chemical reaction in it. In addition, the concentration of the waste water is settled ${ }^{[2]}$.

The urban sewage can be separated into three aspects, the living waste water, the industrial sewage and the public waste water, The flow of them is same as $5 \times 10^{12} \mathrm{~L} / \mathrm{min}$ while they inflow into the recycling facility ${ }^{[3]}$. The maximum of the industrial sewage is $100 \mathrm{mg} / \mathrm{L}$, the living waste water is $30 \mathrm{mg} / \mathrm{L}$, and the public sewage is $10 \mathrm{mg} / \mathrm{L}$ in the same time. The non-potable water's sewage concentration should be less than $1 \mathrm{mg} / \mathrm{L}$, while the concentration can't rise to $0.1 \mathrm{mg} / \mathrm{L}$ in the potable water $^{[4]}$.

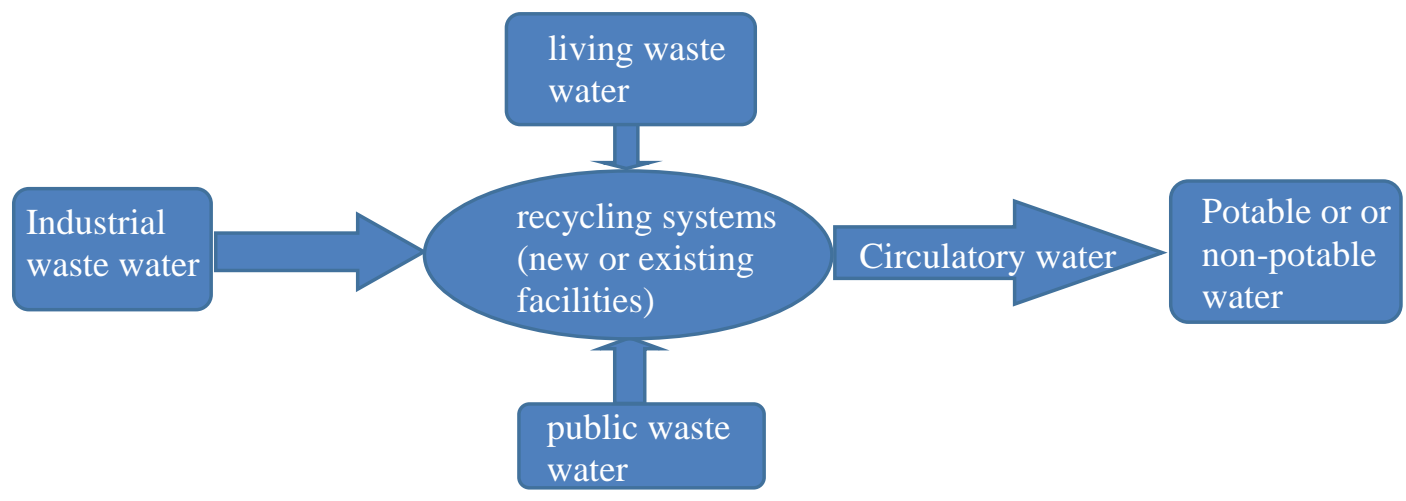

\subsection{Basic Model}

Fig. 2: Sewage treatment’s flow chart

\section{Step1. Model Analysis:}

First of all, in the Statistical Abstract of United States, we figure out seven years of urban water consumption in Billings from 2002 to 2008, Then, we get a series of discrete data consist of living water consumption, industrial water consumption and public water consumption ${ }^{[5]}$. Then we use MATLAB to fit a linear function to urban water consumption of Billings from 2002 to 2008.

Two forces act on the function: Particular year(x), annual urban water consumption(y).

$$
y=0.962642857143 \cdot x-1901.509642857196
$$

Then, we draw out the scatter plot and the fitting curve (as shown in Figure 3).

The predicted result turn out to be that $1.662158 \mathrm{e}+003$ billion cubic meters of urban water will be consumed.

\section{Step2. Living water consumption:}

Two forces act on the function: Particular year(x), annual living water consumption $\left(\mathrm{y}_{1}\right)$.

$$
y_{1}=0.2037 \cdot x-405.1
$$

Then,we draw out the scatter plot and the fitting curve (as shown in Figure 4).

The predicted result turns out to be that $2.670557 \mathrm{e}+002$ billion cubic meters of living water will be consumed. 


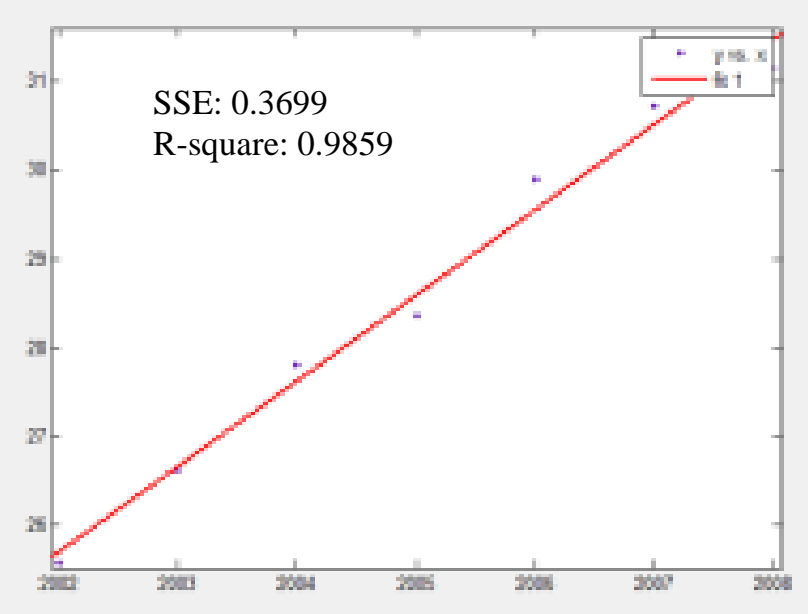

Fig. 3: Urban water consumption

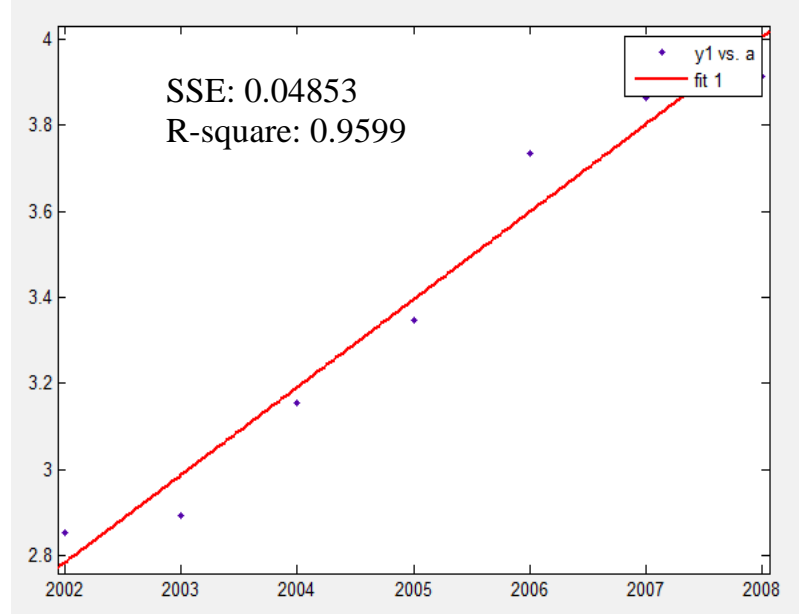

Fig. 4: Living water consumption

\section{Step3. Industrial water consumption:}

Two forces act on the function: Particular year(x), annual Industrial water consumption $\left(\mathrm{y}_{2}\right)$ :

$$
y_{2}=0.405 \cdot x-788.4
$$

Then, we draw out the scatter plot and the fitting curve (as shown in Figure 5).

The predicted result turn out to be that $1.058805 \mathrm{e}+003$ billion cubic meters of industrial water will be consumed.

\section{Step4. Public water consumption:}

Two forces act on the function: Particular year(x), annual public water consumption $\left(\mathrm{y}_{3}\right)$ :

$$
y_{3}=0.3539 \cdot x-708.1
$$

Then, we draw out the scatter plot and the fitting curve (as shown in Figure 6).

The predicted result turn out to be that $3.307979 \mathrm{e}+002$ billion cubic meters of public water will be consumed.

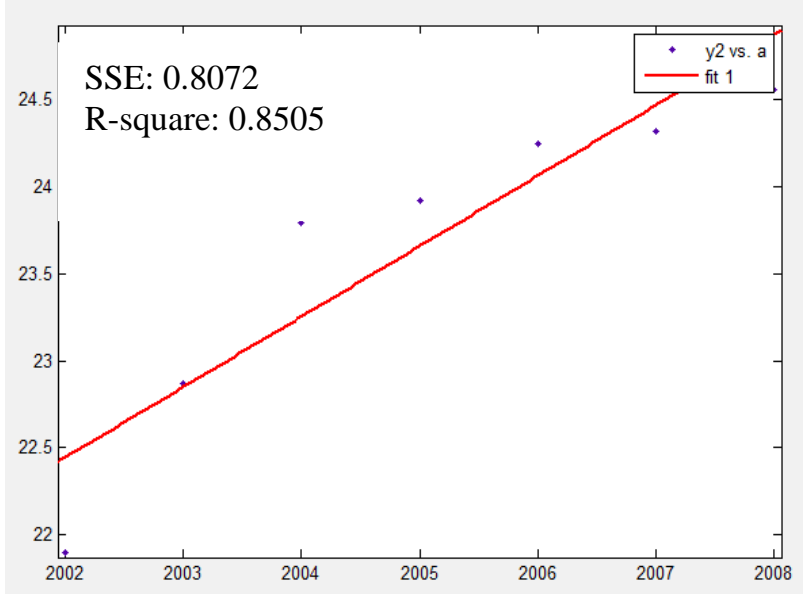

Fig.5: Industrial water consumption

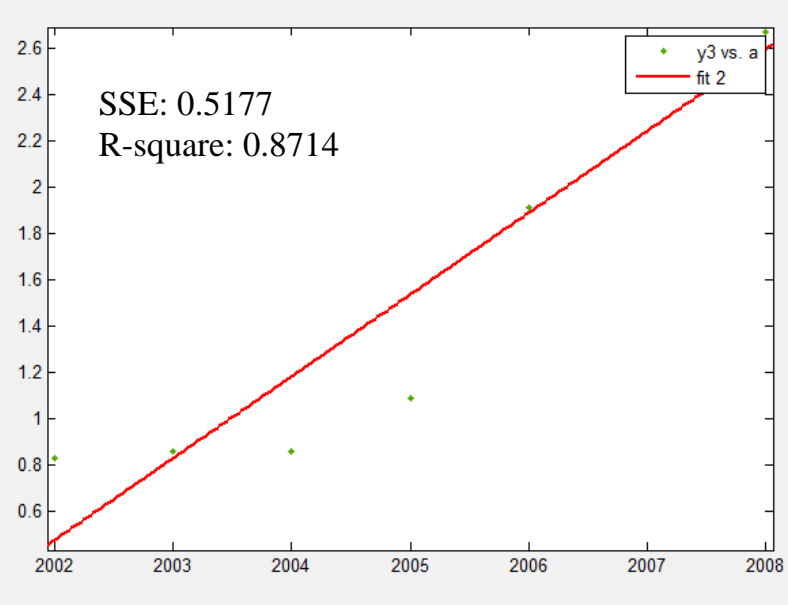

Fig. 6: Public water consumption

Step5. Total of the living,industrial and public water consumption is $1.6566586 e+003$. 
Table 1. Water distribution

\begin{tabular}{ccccc}
\hline Year & $\begin{array}{c}\text { Living water } \\
\left(\mathrm{m}^{3}\right)\end{array}$ & $\begin{array}{c}\text { Industral } \\
\text { water }\left(\mathrm{m}^{3}\right)\end{array}$ & $\begin{array}{c}\text { Public } \\
\text { water }\left(\mathrm{m}^{3}\right.\end{array}$ & $\begin{array}{c}\text { Total water } \\
\left(\mathrm{m}^{3}\right)\end{array}$ \\
\hline 2002 & 2.854 & 21.9 & 0.83 & 25.584 \\
2003 & 2.894 & 22.87 & 0.86 & 26.624 \\
2004 & 3.154 & 23.79 & 0.86 & 27.804 \\
2005 & 3.348 & 23.92 & 1.09 & 28.358 \\
2006 & 3.736 & 24.25 & 1.91 & 29.896 \\
2007 & 3.865 & 24.32 & 2.53 & 30.715 \\
2008 & 3.914 & 24.56 & 2.67 & 31.144 \\
Summation & 23.765 & 165.61 & 10.75 & 200.125 \\
\hline
\end{tabular}

According to the table 1, we separately calculate the water consumption, and figure out the water distribution in Billings.

\section{Sensitivity}

\section{Step1. Fitting of total amount:}

The variance of the linear fitting's result is 0.3699 , and the correlation coefficient is 0.9859 ; The variance of the power function's result is 0.4843 , and the correlation coefficient is 0.9816 . Through the fitting effect of the power function turns to be not very good, they preferably explain the relation between the variables.

\section{Step2. Fitting of components:}

1. Living water consumption: The variance of the linear fitting's result is 0.04853 , and the correlation coefficient is 0.9599 ; The variance of the power function's result is 0.04843 , and the correlation coefficient is 0.9600 . And the fitting effect of the power function is better than linear fitting, they preferably explain the relation between the variables.

2. Industrial water consumption: The variance of the linear fitting's result is 0.8072 , and the correlation coefficient is 0.8505 ; The variance of the power function's result is 0.8579 , and the correlation coefficient is 0.8411 . Through the fitting effect of the power function turns to be not very good, they preferably explain the relation between the variables.

3. Public water consumption: The variance of the linear fitting's result is 0.8072 , and the correlation coefficient is 0.8505 ; The variance of the power function's result is 0.8579 , and the correlation coefficient is 0.8411 . The fitting effect of the power function fit well with the linear fitting, they preferably explain the relation between the variables.

\section{Conclusion}

The cost of water treatment of the original equipment is about 10 million. New equipment to deal with the cost of about 6 million, each time unit the advanced equipment can saves about 4 million. Due to the longer service life of the treatment equipment. We conclude that the budget for upgrading equipment can be accepted within 50 million.

\section{References}

[1] Weiwen Huang, Hua Wang, Changjun Yu, Peng He. Thermal and fluid machinery [M]. China Electric Power Press, Oct, 2007. 69-106.

[2] Jinhai Li, Lizhen Tan, Renhua Cai. Hot spring water temperature change control Mathematical model [J]. Joumal of Qiongzhou University, Apr 28th, 2006. 
[3] Guosheng Dai. Heat transfer [J]. Higher Education Press, Sept, 1999. 56-59

[4] Songling Wang, Benyuan Wu, Song Fu, Yukun Lv. Fluid Mechanics [J]. China Electric Power Press, Oct, 2004.

[5] Quangui Fan, Weiping Yan, Shunlin Yan, Jun Wang. Principles of Boiler [J].China Electric Power Press, Sept, 2008. 